\title{
Sorption of phenol from aqueous solutions using acid-treated rice husk
}

\author{
S. B. Daffalla ${ }^{1}$, H. Mukhtar ${ }^{1}$ \& M. S. Shaharun ${ }^{2}$ \\ ${ }^{1}$ Department of Chemical Engineering, \\ Universiti Teknologi PETRONAS, Malaysia \\ ${ }^{2}$ Department of Fundamental and Applied Science, \\ Universiti Teknologi PETRONAS, Malaysia
}

\begin{abstract}
In this study, the development of low-cost adsorbent material from cheap abundant rice husk was developed via sulfuric acid treatment. The physiochemical properties and functional groups characterization of the adsorbents were evaluated. The effects of $\mathrm{pH}$ and contact time were studied in batch experiments. It was found that sulfuric acid treatment affects the pore size distribution, surface area, morphological structure and functional groups of the rice husk. Analysis showed that the surface area of rice husk was increased 7 times from 7.14 to $50.17 \mathrm{~m}^{2} \cdot \mathrm{g}^{-1}$. In addition, the surface structure of the rice husk was changed from a non-porous to a porous surface after treatment. On the other hand, the uptake of phenol onto the rice husk was increased from 20.06 to $48.62 \%$ after treatment. Further, the percentage adsorption of phenol increased with the increase of the contact time. The maximum uptake of phenol can be obtained at $\mathrm{pH}$ 4. The equilibrium data were well described by the Freundlich model, while the kinetic data were well fitted to the models of pseudo second order and Elovich, and followed closely by the Elovich chemisorption model.

Keywords: acid-treated rice husk, phenol removal, adsorption, wastewater treatment.
\end{abstract}

\section{Introduction}

The presence of hazardous chemicals in the environment continues to be an important concern. The demand for more stringent control and protection of our water resources from pollution has mounted steadily in recent decades [1]. 
Phenol, a class of organic compounds, has been known as a common and hazardous contaminant in water environment. Phenol constitutes the $11^{\text {th }}$ of the 126 chemicals, which have been designated as priority pollutants by the US Environmental Protection Agency (USEPA) [2]. The content of phenols in industrial wastewater is usually in the range of $0.1-6800 \mathrm{mg}^{-1}$ [3]. The allowable discharge limit for phenol is $0.1 \mathrm{mg} . \mathrm{L}^{-1}$ and $0.001 \mathrm{mg} . \mathrm{L}^{-1}$ (Standard A) set by the USEPA and the Malaysia Environmental Quality Act (MEQA), 1974 respectively [4].

Various methods such as microbial degradation, adsorption, chemical oxidation, incineration, solvent extraction, membranes (ultrafiltration, nanofiltration, reverse osmosis) and advanced oxidation processes (UV photocatalysis, Fenton) have previously been used for removal of phenol from wastewater [5, 6]. Among those methods, adsorption process has been identified as the best for removing phenolic compounds from aqueous streams. To the present day, activated carbon is the most widely used adsorbent because it has good capacity for adsorption of phenol from wastewater [7]. In spite of this, it suffers from a number of disadvantages. Activated carbon is expensive, and the higher the quality the greater the cost [8]. Consequently, there has been a growing interest in developing and implementing various potential adsorbents for the removal of phenol from water, and researchers are always in a hunt for developing more suitable, efficient, cheap and easily accessible types of adsorbents, particularly from the waste materials.

The abundance and availability of agricultural by-products make them good sources of cheap raw materials for natural adsorbents. Rice husk, an agricultural waste, has been reported as a good adsorbent for many metals and basic dyes [9]. According to the statistics compiled by the Malaysian Ministry of Agriculture, there are more than 408,000 ton of rice husk produced in Malaysia annually [10]. Rice husk consists of $32.24 \%$ cellulose, $21.44 \%$ hemicelluloses and $21.34 \%$ lignin [10]. The cellulose, hemicellulose and lignin forming a very stable matrix structure. The inner surface of rice husk is smooth, and may contain wax and natural fats that provide good shelter for the grain. On the other hand, the presence of these impurities on the inner surface of rice husk also affects the adsorption properties of rice husk, both chemically and physically [11]. Therefore, the removal of these impurities can be expected to improve the adsorption properties of rice husk.

Chemical modification of rice husk surface is thus necessary to upgrade or improve the adsorption properties [11]. Treatment of rice husk with sulfuric acid has been established to improve the adsorption properties. As a result of acid wash, inorganic materials such as carbonate and silica from the surface of raw rice husk [12]. The removal of the surface impurities also improves the surface roughness of the fibers or particles, thus opening more hydroxyl groups and other reactive functional groups on the surface. The pre-treatment of rice husk using sulfuric acid, as one of the most effective reagents for this structural breakdown, is able to remove lignin and hemicellulose, reduce cellulose crystallinity, and increase the porosity or surface area. 
The objective of this study was to modify rice husk with sulfuric acid to enhance its ability to adsorb phenol, then the characterization of the developed adsorbent was studied. Furthermore, the adsorption process was investigated as a function of $\mathrm{pH}$, initial phenol concentration, contact time and adsorbent dose. The kinetic and isotherm studies were also studied.

\section{Material and methods}

\subsection{Preparation of adsorbents}

The raw material, rice husk (RH), was obtained from a nearby rice mill. The rice husk was washed thoroughly with distilled water to remove adhering soil and clay, and then dried in air at $105^{\circ} \mathrm{C}$ in an oven for 24 hours. Sample of rice husk was mixed with $13 \mathrm{M} \mathrm{H}_{2} \mathrm{SO}_{4}$ at $180^{\circ} \mathrm{C}$ for $20 \mathrm{~min}$ at $180 \mathrm{rpm}$ [13]. Then the acid husk slurry was washed with distilled water to remove any excess of acid and dried at $50-60^{\circ} \mathrm{C}$ in the oven for 24 hours. The developed adsorbent was designated as $\mathrm{RH}_{2} \mathrm{SO}_{4}$.

\subsection{Characterization of adsorbents}

The adsorbents were characterized in terms of morphological characteristics using Scanning Electron Microscope (SEM) model LE01430VP. The surface area and pore size distribution of the adsorbents were obtained by the Micromeritics ASAP 2020 gas adsorption surface analyzer. In addition, the functional groups present on the adsorbent's surface were determined using a Fourier Transform Infrared spectrophotometer (FTIR) model 8400S. The spectra range chosen was from 4000 to $400 \mathrm{~cm}^{-1}$.

\subsection{Batch adsorption studies}

Batch adsorption experiments were performed using adsorbent dose of 10 g.L. $\mathrm{L}^{-1}$. The sorption study was performed using a mechanical shaker for a period of 24 hours at $195 \mathrm{rpm}$ and ambient temperature. The phenol sample $100 \mathrm{ml}$ of $100 \mathrm{mg} . \mathrm{L}^{1}$ at normal $\mathrm{pH}$ was placed in a $250 \mathrm{ml}$ glass Erlenmeyer flask and the flask was attached to the shaker. The suspensions in all sorption assays were filtered to remove any suspended adsorbent. The initial and final concentrations of phenol were determined by HPLC (Agilent 1100 series) equipped with a Diode Array Detector (DAD). The components were separated on a Zorbax SB C18 column $(3 \times 250 \mathrm{~mm})$. The effect of $\mathrm{pH}(2-10)$ was studied by adjusting the $\mathrm{pH}$ of phenol solution using dilute $\mathrm{HCl}$ and $\mathrm{NaOH}$ solutions at ambient temperature.

The percentage of phenol removal and equilibrium adsorption uptake, $\mathrm{q}_{\mathrm{e}}\left(\mathrm{mg} \cdot \mathrm{g}^{-1}\right)$ were calculated using the following relationships:

$$
\text { Removal Efficiency }(\%)=\frac{\left(C_{o}-C_{t}\right)}{C_{o}} \times 100
$$




$$
\text { Amount Adsorbed } \begin{aligned}
\left(q_{e}\right)= & \frac{\left(C_{o}-C_{e}\right) V}{W} \\
& (\text { mg of aadsorbate / g of adsorbant) }
\end{aligned}
$$

where, $C_{o}$ and $C_{e}$ (mg. $\mathrm{L}^{-1}$ ) are the initial and equilibrium liquid-phase concentrations of phenol, respectively, $C_{t}$ (mg. $\mathrm{L}^{-1}$ ) is the concentration of phenol at time $\mathrm{t}, \mathrm{V}$ is the volume of the solution (L) and $\mathrm{W}$ is the mass of dry adsorbent (g).

For kinetic studies, the adsorption data were analyzed using three different kinetic models namely pseudo first-order, pseudo second-order and Elovich models (Table 1), while the equilibrium data was analyzed using commonly known adsorption isotherms, the Freundlich and Langmuir models (Table 2).

To compare the validity of the isotherm and kinetic equations more definitely, the average percentage errors $(A P E)$ were calculated using [14]:

$$
\operatorname{APE}(\%)=\frac{\sum_{i=1}^{N}\left|\left(q_{\text {exp }}-q_{c a l}\right) / q_{\text {exp }}\right|}{N} \times 100
$$

where $\mathrm{q}_{\exp }$ and $\mathrm{q}_{\mathrm{cal}}$ (mg. $\mathrm{g}^{-1}$ ) represent the experimental and calculated adsorption

\begin{tabular}{|c|c|c|c|}
\hline $\begin{array}{l}\text { Kinetic } \\
\text { model }\end{array}$ & Equation & Parameters & Ref. \\
\hline $\begin{array}{l}\text { Pseudo- } \\
\text { first } \\
\text { order }\end{array}$ & $\ln \left(q_{e}-q_{t}\right)=\ln \left(q_{e}\right)-k_{1} t$ & $\begin{array}{l}\mathrm{q}_{\mathrm{e}}\left(\mathrm{mg} \mathrm{g}^{-1}\right) \text { : } \\
\text { equilibrium } \\
\text { adsorption capacity } \\
\mathrm{q}_{\mathrm{t}}\left(\mathrm{mg}^{-1} \mathrm{~g}^{-1}\right) \text { : amount } \\
\text { of adsorbate } \\
\text { adsorbed at time } \mathrm{t} \\
(\mathrm{min}) \\
\mathrm{k}_{1}\left(\mathrm{~min}^{-1}\right) \text { : pseudo- } \\
\text { first-order-rate } \\
\text { constant }\end{array}$ & [15] \\
\hline $\begin{array}{l}\text { Pseudo- } \\
\text { second } \\
\text { order }\end{array}$ & $\frac{t}{q_{t}}=\frac{1}{k_{2} q_{e}^{2}}+\frac{1}{q_{e}} t$ & $\begin{array}{l}\mathrm{k}_{2}\left(\mathrm{~g} \cdot \mathrm{mg}^{-1} \cdot \mathrm{min}^{-1}\right): \\
\text { pseudo-second- } \\
\text { order rate constant }\end{array}$ & [16] \\
\hline Elovich & $q_{t}=\frac{1}{b} \ln (a b)+\frac{1}{b} \ln (t)$ & $\begin{array}{l}\text { a }\left(\mathrm{mg}^{-1} \mathrm{~g}^{-1} \cdot \mathrm{min}^{-1}\right) \text { : } \\
\text { initial sorption rate } \\
\text { constant } \\
\mathrm{b}\left(\mathrm{g} \cdot \mathrm{mg}^{-1}\right) \text { : } \\
\text { desorption constant }\end{array}$ & [15] \\
\hline
\end{tabular}
capacity value, respectively, and $N$ the number of data points.

Table 1: $\quad$ Kinetic equations used in this study. 
Table 2: $\quad$ Isotherm equation used in this study.

\begin{tabular}{|c|c|l|c|}
\hline $\begin{array}{c}\text { Isotherm } \\
\text { model }\end{array}$ & Equation & \multicolumn{1}{|c|}{ Parameters } & Ref. \\
\hline Freundlich & $q_{e}=K_{F} C_{e}^{1 / n}$ & $\begin{array}{l}\mathrm{q}_{\mathrm{e}}\left(\mathrm{mg}^{\mathrm{g}} \mathrm{g}^{-1}\right) \text { : equilibrium adsorption } \\
\text { capacity; } \mathrm{K}_{\mathrm{F}}\left(\mathrm{mg}^{1-1 / \mathrm{n}} \cdot \mathrm{L}^{1 / \mathrm{n}} \cdot \mathrm{g}^{-1}\right): \\
\text { Freundlich constant; } \mathrm{n} \text { : Freundlich } \\
\text { constant }\end{array}$ & {$[15]$} \\
\hline Langmuir & $q_{e}=\frac{q_{m} K_{L} C_{e}}{1+K_{L} C_{e}}$ & $\begin{array}{l}\mathrm{q}_{\mathrm{m}}\left(\mathrm{mg} \cdot \mathrm{g}^{-1}\right) \text { : the maximum adsorption } \\
\text { capacity; } \mathrm{K}_{\mathrm{L}}\left(\mathrm{L} \cdot \mathrm{mg}^{-1}\right): \text { Langmuir } \\
\text { adsorption constant, adsorption } \\
\text { equilibrium constant }\end{array}$ \\
\hline
\end{tabular}

\section{Results and discussions}

\subsection{Surface physical morphology}

SEM was employed to observe the surface physical morphology of the adsorbents. Fig. 1(a) shows the morphological features of outer epidermis raw rice husk, which is well organized in structure that resembles rolling hills. However after sulfuric acid treatment, the surface characteristic was slightly $\mathrm{H}$ and wash the inorganic materials from the surface of rice husk. As a result, the surface characteristic of rice husk would have been changed.
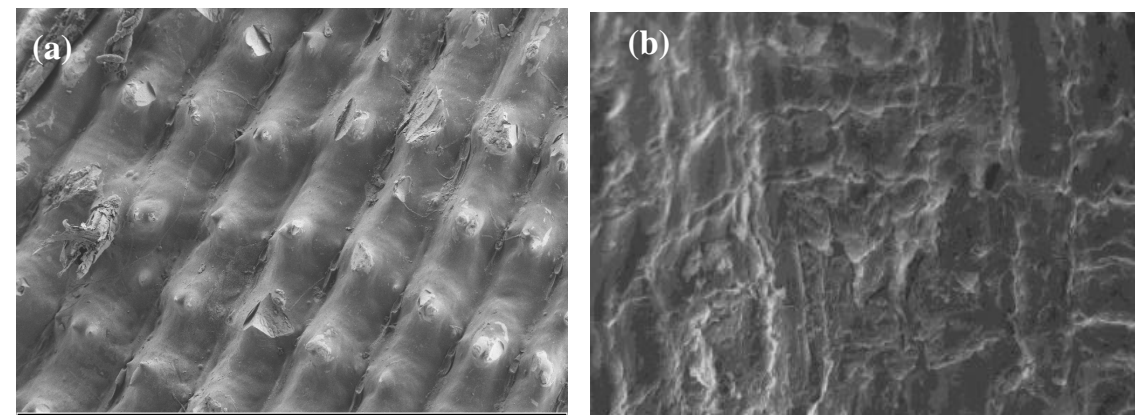

Figure 1: $\quad$ SEM for (a) $\mathrm{RH}$ and (b) $\mathrm{RH}_{2} \mathrm{SO}_{4}$ magnified 1000 times.

\subsection{Surface area and pore size distribution analysis}

\subsubsection{N2 Adsorption-desorption isotherms}

Fig. 2 illustrates adsorption/desorption isotherms of $\mathrm{N}_{2}$ at $-196^{\circ} \mathrm{C}$ on rice husk $(\mathrm{RH})$ and sulfuric acid treated rice husk $\left(\mathrm{RH}_{2} \mathrm{SO}_{4}\right)$. Fig. 2(a) shows that $\mathrm{RH}$ adsorbent possessed combination of types II and IV isotherms of the International Union of Pure and Applied Chemistry classification (IUPAC), which is characteristic of non-porous or macroporous and mesopores solid [17]. 
On the other hand, from the shape of the isotherms in Fig. 2(b), it can clearly be seen that there were major changes in the porous structure of rice husk after treatment with $\mathrm{H}_{2} \mathrm{SO}_{4}$. Thus, once the rice husk treated with the $\mathrm{H}_{2} \mathrm{SO}_{4}$, a porous structure starts to develop and the pore size and distribution depend on the chemical treatment. Indeed, the shapes of the isotherms in Fig. 2(b) seem to belong to a mixed type in the IUPAC classification; type II and type I, indicative of macroporous and micropore material [17]. Besides, as another major observation, it could be mentioned. The shapes of the hysteresis slopes of RH and $\mathrm{RH}_{2} \mathrm{SO}_{4}$ are different (Fig. 2). Indeed, a sharp inflection of 0.8-1.0 in between $P / P_{0}$ and a typical $\mathrm{H} 1$ type hysteresis loop is observed for the RH. However, a slit-like pores for which adsorbent-adsorbate pair which would yield a type $\mathrm{H} 3$ hysteresis loop is observed for the $\mathrm{RH}_{2} \mathrm{SO}_{4}$.
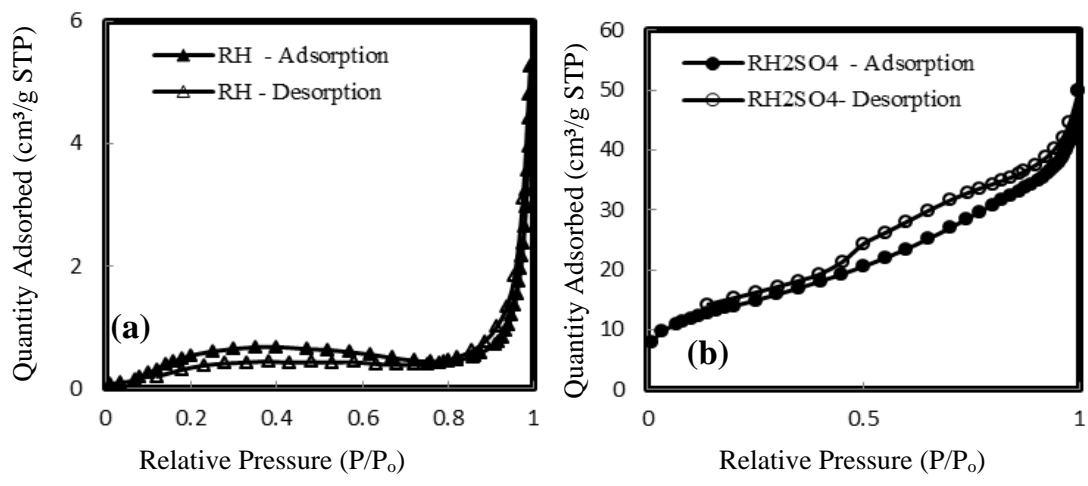

Figure 2: $\quad$ Hysteresis loops of (a) $\mathrm{RH}$ and (b) $\mathrm{RH}_{2} \mathrm{SO}_{4}$.

\subsubsection{Pore structure analysis}

In order to compare the textural properties of adsorbents, the parameter obtained from BET surface area, pore volume, pore diameter and microporosity are tabulated in Table 3. This table shows that the surface area of $\mathrm{RH}_{2} \mathrm{SO}_{4}$ increased approximately 7 times from 7.14 to $50.17 \mathrm{~m}^{2} \cdot \mathrm{g}^{-1}$, comparing with the raw material. Meanwhile, the pore volume and the pore diameter of the $\mathrm{RH}$ increased from 0.0055 to $0.066 \mathrm{~cm}^{3} \cdot \mathrm{g}^{-1}$ and 3.08 to $5.25 \mathrm{~nm}$, respectively. From these results it can be concluded that the strong mineral acid such as sulfuric acid $\left(\mathrm{H}_{2} \mathrm{SO}_{4}\right)$ would able to degrade more cellulose hemicellulose and lignin from the surface of rice husk which result in formation of higher surface area compared to the rice husk.

Dealing with the pore size distribution of the adsorbents, shown in Fig. 3; the pore size distributions of $\mathrm{RH}$ and $\mathrm{RH}_{2} \mathrm{SO}_{4}$ samples were calculated from the $\mathrm{N}_{2}$ adsorption isotherm following the Barrett-Joyner-Halenda (BJH) method with calibration. It is clearly shown in Fig. 3, RH revealed the relatively broad pore distribution centred at approximately $52.2 \mathrm{~nm}$. While for acid treated sample, $\mathrm{RH}_{2} \mathrm{SO}_{4}$, the pore distribution is relatively narrow and shifted further into the mesopores region, centred at $4 \mathrm{~nm}$ and $15.8 \mathrm{~nm}$. These results are confirmed by 
Table 3: $\quad$ Pore textural characteristics of adsorbent.

\begin{tabular}{|l|l|l|l|l|l|l|}
\hline \multirow{2}{*}{ Adsorbent } & $\begin{array}{l}\text { BET } \\
\text { surface } \\
\text { area } \\
\left(\mathrm{m}^{2} \cdot \mathrm{g}^{-1}\right)\end{array}$ & $\begin{array}{l}\text { Micro- } \\
\text { pore } \\
\text { area } \\
\left(\mathrm{m}^{2} \cdot \mathrm{g}^{-1}\right)^{\mathrm{a}}\end{array}$ & $\begin{array}{l}\text { Micro- } \\
\text { pore } \\
\text { volume } \\
\left(\mathrm{cm}^{3} \cdot \mathrm{g}^{-1}\right)^{\mathrm{a}}\end{array}$ & $\begin{array}{l}\text { Total } \\
\text { pore } \\
\text { volume } \\
\left(\mathrm{cm}^{3} \cdot \mathrm{g}^{-1}\right)^{\mathrm{b}}\end{array}$ & $\begin{array}{l}\text { Average } \\
\text { pore } \\
\text { diameter } \\
(\mathrm{nm})^{\mathrm{c}}\end{array}$ & $\begin{array}{l}\mathrm{M} \\
(\%)^{\mathrm{d}}\end{array}$ \\
\hline $\mathrm{RH}$ & 7.1365 & 1.4371 & 0.00 & 0.005496 & 3.0804 & 0.00 \\
\hline $\mathrm{RH}_{2} \mathrm{SO}_{4}$ & 50.1657 & 3.1743 & 0.001044 & 0.065836 & 5.24951 & 1.59 \\
\hline
\end{tabular}

${ }^{\mathrm{a}}$ Applying BJH model; ${ }^{\mathrm{b}}$ Single point adsorption total pore volume; ${ }^{\mathrm{c}}$ Adsorption average pore width (4V/A by BET); ${ }^{\mathrm{d}} \mathrm{M}$ (Microporosity) $=($ Micropore volume/Total pore volume) $\times 100 \%$.

surface morphological of these adsorbents (Fig. 1). Indeed, Fig. 1(a) showed that the surface structure of the rice husk changes from a non-porous one, with a starlike pattern, into a porous surface with what seems to be from the surface view as mesopores after acid treatment using $\mathrm{H}_{2} \mathrm{SO}_{4}$ (Fig. 1(b)), due to destroyed of cellulose-ligning matrix.

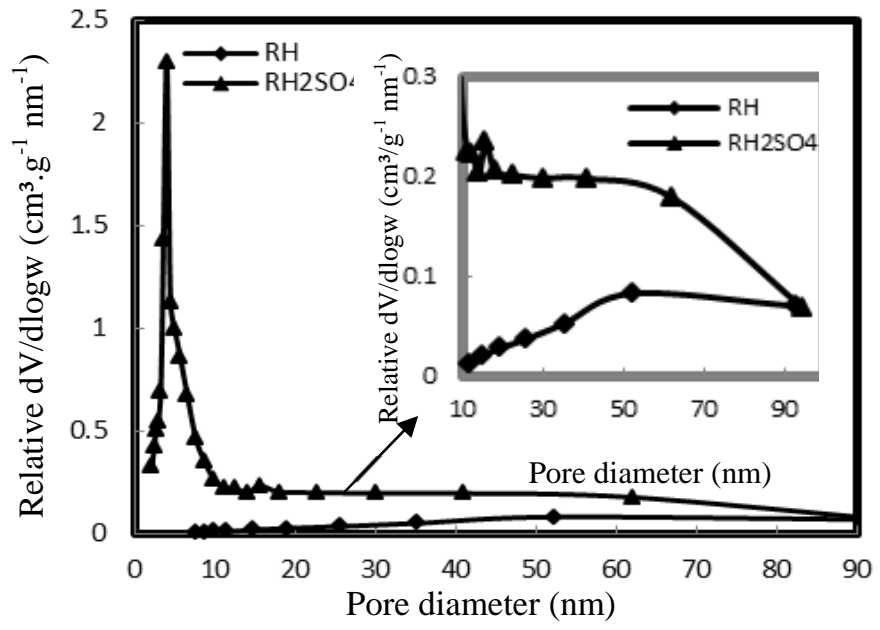

Figure 3: $\quad$ Pore size distribution of $\mathrm{RH}$ and $\mathrm{RH}_{2} \mathrm{SO}_{4}$.

\subsection{Surface functional groups analysis}

The chemical structure of adsorbent is of vital importance in understanding the adsorption process. Fourier Transform Infrared Spectrophotometer (FTIR) technique is an important tool to identify the characteristic functional groups, which are instrumental in adsorption of phenol. The FTIR spectra of these adsorbents are shown in Fig. 4. As seen in this figure, the adsorption peak around $3404.31 \mathrm{~cm}^{-1}$ indicates the existence of free hydroxyl groups. In $\mathrm{RH}$, the $\mathrm{C}-\mathrm{H}$ stretching vibration around $2925.81 \mathrm{~cm}^{-1}$ indicates the presence of alkane 
functional group. The peaks around $1641.31-1737.74 \mathrm{~cm}^{-1}$ correspond to $\mathrm{C}=\mathrm{O}$ stretching that may be attributed to the hemicelluloses and lignin aromatic groups [18]. The $\mathrm{C}=\mathrm{C}$ stretching vibrations between $1546.80-1652.88 \mathrm{~cm}^{-1}$ are indicative of alkenes and aromatic functional groups. The peaks around $1461.94 \mathrm{~cm}^{-1}$ indicate the presence of $\mathrm{CH}_{2}$ and $\mathrm{CH}_{3}$ groups while those at 1380 $\mathrm{cm}^{-1}$ are indicative of $\mathrm{CH}_{3}$ [18]. A peak at $1379.01 \mathrm{~cm}^{-1}$ band may be attributed to aromatic $\mathrm{CH}$ and carboxyl-carbonate structures. The peaks in 1153.35$1300 \mathrm{~cm}^{-1}$ correspond to vibration of $\mathrm{CO}$ group in lactones. The peaks around $1238.21,1080.06$ and $862.12-476.38 \mathrm{~cm}^{-1}$ correspond to $\mathrm{CHOH}$ stretching, Si$\mathrm{O}-\mathrm{Si}$ stretching and Si-H groups, respectively. The presence of polar groups on the surface is likely to provide considerable cation exchange capacity to the adsorbent [18].

On the other hand as can be inferred from the FTIR analysis for the $\mathrm{RH}_{2} \mathrm{SO}_{4}$, the relative intensity of a band at $3400-2000 \mathrm{~cm}^{-1}$ decrease compared to the raw rice husk (Fig. 4), due to destruction of carboxyl groups by acid treatment. In addition, a band at 1090-1010 $\mathrm{cm}^{-1}$ attributed to silica functional group Si-O$\mathrm{Si}$, is less intense than that of the raw rice husk at $1080 \mathrm{~cm}^{-1}$ as a result of acid wash inorganic materials such as carbonate and silica from the surface of the rice husk [12].

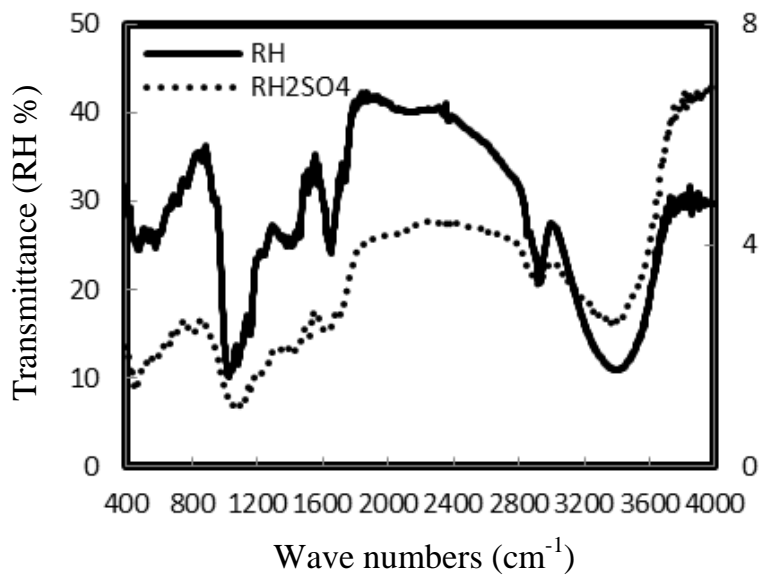

Figure 4: $\quad$ FTIR spectra of $\mathrm{RH}$ and $\mathrm{RH}_{2} \mathrm{SO}_{4}$.

\subsection{Effect of acid treatment on uptake of phenol}

Fig. 5 shows the effect of $\mathrm{H}_{2} \mathrm{SO}_{4}$ treatment towards the performance of the adsorbent in removing phenol. From this figure it was found that the uptake of phenol onto $\mathrm{RH}_{2} \mathrm{SO}_{4}$ (48.62\%) was higher compare to rice husk (20.06\%). This indicates that the feasibility of sulphuric acid treated rice husk $\left(\mathrm{RH}_{2} \mathrm{SO}_{4}\right)$ as adsorbent for removal of phenol from aqueous solution. 


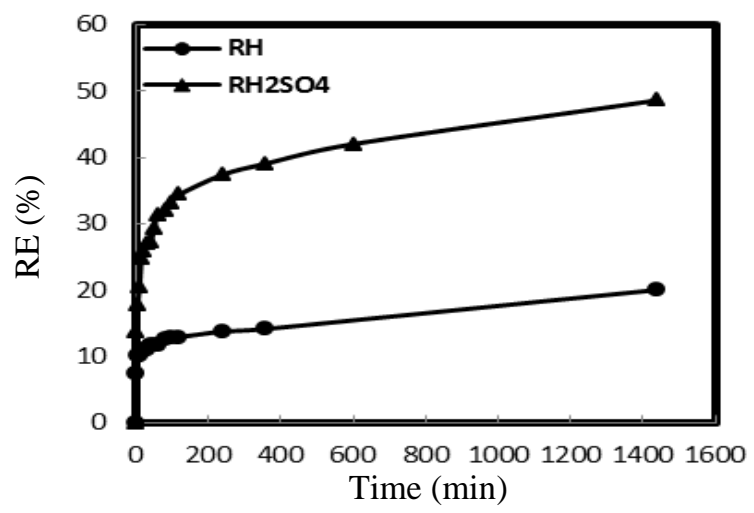

Figure 5: $\quad$ Effect of contacting time on uptake of phenol on $\mathrm{RH}$ and $\mathrm{RH}_{2} \mathrm{SO}_{4}$.

\subsection{Effect of $\mathbf{p H}$}

Fig. 7 depicts the effect of $\mathrm{pH}$ on removal efficiency of phenol using $\mathrm{RH}_{2} \mathrm{SO}_{4}$. The effect of $\mathrm{pH}$ was studied over the $\mathrm{pH}$ range of 2 to10. From this figure, it is clear that a lower $\mathrm{pH}$ value is favorable for higher sorption of phenol and the maximum uptake of phenol take place at $\mathrm{pH}$ 4. At $\mathrm{pH} 5.58$ (normal $\mathrm{pH}$ ) and above, the removal efficiency seems to remain constant. A decrease in $\mathrm{pH}$ probably results in a reduction of the negative charges at the surface of adsorbents. Because at lower $\mathrm{pH}$ the hydration shell exhibited by adsorbents can be positively charged by the hydronium ion in the solution. However, in the higher $\mathrm{pH}$ range phenol forms salts, which readily ionize to form negative charge on the phenolic group. At the same time the presence of $\mathrm{OH}^{-}$ions on the adsorbent prevents the uptake of phenolate ions [19]. Similar behavior has been reported by Mahvi et al. [19], for the removal of phenol from aqueous solution by rice husk and rice husk ash. In general adsorption of phenol is much higher at low $\mathrm{pH}$ (undissociated form of phenol) than high $\mathrm{pH}$ (dissociated form of phenol).

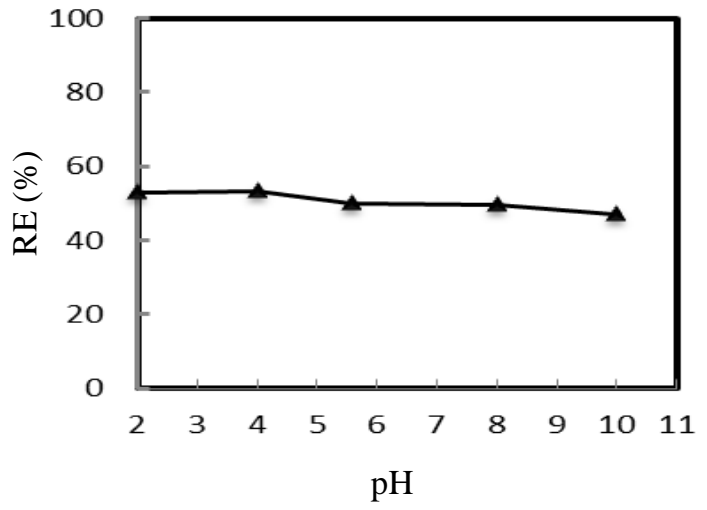

Figure 6: $\quad$ Effect of $\mathrm{pH}$ on the removal of phenol on $\mathrm{RH}_{2} \mathrm{SO}_{4}$. 


\subsection{Kinetic study for the removal of phenol}

The kinetic of the adsorption data were analyzed using the pseudo-first order, pseudo-second order and Elovich equations (Table 1). All the correlation coefficient and constants obtained for the models are summarized in (Table 4).

Firstly, for the pseudo-first order model, the $R^{2}$ value and the APE were 0.646 and $89.2 \%$, respectively (Table 4$)$. Furthermore, the experimental value $\left(q_{e, \exp }\right)$ does not agree with the calculated one which indicate that the adsorption of phenol on the $\mathrm{RH}_{2} \mathrm{SO}_{4}$ is not first-order reaction. For the pseudo-second order kinetic model, as can be seen from (Table 4) the coefficient of determination $R^{2}$ was almost equal to unity. Further, the low value of the APE (11.24\%) for phenol adsorption proves the best agreement of pseudo-second order model describing adsorption of phenol on the $\mathrm{RH}_{2} \mathrm{SO}_{4}$. On the other hand, higher $R^{2}$ value $(0.976)$ for the Elovich model was obtained (Table 4). The calculated $q_{e}$ value agreed with experimental $\left(q_{e, \text { exp }}\right)$ one. Moreover, the lowest APE (3.23\%) confirms the good applicability of the Elovich model, which agrees with chemisorption as the rate-limiting mechanism, for phenol adsorption on the $\mathrm{RH}_{2} \mathrm{SO}_{4}$. Overall, comparison with the models used to describe adsorption kinetics, indicates that the Elovich model is the best model to describe the liquid phase adsorption of phenol on the $\mathrm{RH}_{2} \mathrm{SO}_{4}$ followed by the pseudo-second order.

Table 4: $\quad$ Kinetic constants for phenol adsorbed on $\mathrm{RH}_{2} \mathrm{SO}_{4}$.

\begin{tabular}{|c|c|c|}
\hline \multirow{2}{*}{ Model } & Parameters & $\mathrm{RH}_{2} \mathrm{SO}_{4}$ \\
\hline & $\mathrm{q}_{\mathrm{e}, \exp }\left(\mathrm{mg} \cdot \mathrm{g}^{-1}\right)$ & 5.2834 \\
\hline \multirow{4}{*}{ Pseudo -first order } & $\mathrm{q}_{\mathrm{e}, \mathrm{cal}}\left(\mathrm{mg} \cdot \mathrm{g}^{-1}\right)$ & 2.4967 \\
\hline & $\mathrm{K}_{1}\left(\mathrm{~min}^{-1}\right)$ & 0.0019 \\
\hline & $\mathrm{R}^{2}$ & 0.6457 \\
\hline & APE (\%) & 89.204 \\
\hline \multirow{4}{*}{ Pseudo -second order } & $\mathrm{q}_{\mathrm{e}, \mathrm{cal}}\left(\mathrm{mg} \cdot \mathrm{g}^{-1}\right)$ & 4.2315 \\
\hline & $\mathrm{K}_{2}\left(\mathrm{~g} \mathrm{mg}^{-1} \cdot \mathrm{min}^{-1}\right)$ & 0.0204 \\
\hline & $\mathrm{R}^{2}$ & 0.9988 \\
\hline & APE (\%) & 11.236 \\
\hline \multirow{5}{*}{ Elovich } & $\mathrm{q}_{\mathrm{e}, \mathrm{cal}}\left(\mathrm{mg} \cdot \mathrm{g}^{-1}\right)$ & 4.4451 \\
\hline & $\mathrm{A}\left(\mathrm{mg} \cdot \mathrm{g}^{-1} \mathrm{~min}^{-1}\right)$ & 5.5332 \\
\hline & $\mathrm{b}\left(\mathrm{g} . \mathrm{mg}^{-1}\right)$ & 1.9773 \\
\hline & $\mathrm{R}^{2}$ & 0.9756 \\
\hline & APE (\%) & 3.2266 \\
\hline
\end{tabular}

\subsection{Adsorption equilibrium study}

In the present work, the data from the adsorption isotherm of phenol onto $\mathrm{RH}_{2} \mathrm{SO}_{4}$ was modeled by the Langmuir and Freundlich equations (Table 2). Sorption isotherm constants and correlation coefficient are tabulated in (Table 5). Table 5 indicates that there is a slight deviation from linearity using the Langmuir isotherm model for describing phenol adsorption by $\mathrm{RH}_{2} \mathrm{SO}_{4}$ 
$\left(R^{2}>0.9994\right)$. Nevertheless, the higher value of the APE (13.28\%), indicate that the inadequacy of isotherm model to explain the adsorption process. Comparatively, Freundlich isotherm model gives better descriptions for phenol adsorption data onto $\mathrm{RH}_{2} \mathrm{SO}_{4}\left(\mathrm{R}^{2}=0.997\right)$. The higher value of the intercept, $K_{F}$, in Table 5 showed easy uptake of phenol from aqueous solution, while the value of $n$ (1.22) indicated that the $\mathrm{RH}_{2} \mathrm{SO}_{4}$ is moderately adsorbent for phenol.

Table 5: $\quad$ Isotherms constants for phenol adsorbed on $\mathrm{RH}_{2} \mathrm{SO}_{4}$.

\begin{tabular}{|l|c|c|c|c|}
\hline Model & \multicolumn{4}{|c|}{ Parameters } \\
\hline \multirow{2}{*}{ Langmuir } & $\mathrm{q}_{\max }\left(\mathrm{mg} \cdot \mathrm{g}^{-1}\right)$ & $\mathrm{K}_{\mathrm{L}}\left(\mathrm{L}^{-1} \mathrm{mg}^{-1}\right)$ & $\mathrm{R}^{2}$ & APE (\%) \\
\cline { 2 - 5 } & 33.142 & 0.0053 & 0.9994 & 13.282 \\
\hline \multirow{2}{*}{ Freundlich } & $\mathrm{K}_{\mathrm{F}}\left(\mathrm{mg}^{1-1 / \mathrm{n}} \mathrm{L}^{1 / \mathrm{n}} \cdot \mathrm{g}^{-1}\right)$ & $\mathrm{n}$ & $\mathrm{R}^{2}$ & APE (\%) \\
\cline { 2 - 5 } & 0.2416 & 1.2205 & 0.9972 & 6.849 \\
\hline
\end{tabular}

\section{Conclusion}

The present study has shown the feasibility of sulfuric acid treated rice husk $\left(\mathrm{RH}_{2} \mathrm{SO}_{4}\right)$ as adsorbent for removal of phenol from aqueous solution. It was found that acid treatment affects the pore size distribution, surface area and functional groups of the rice husk. The surface area of rice husk increased from 7.14 to $50.17 \mathrm{~m}^{2} \cdot \mathrm{g}^{-1}$ after treatment. In addition, the surface structure of the rice husk after treatment was changed from a non-porous one into a porous surface. The ability of the $\mathrm{RH}_{2} \mathrm{SO}_{4}$ to bind phenol was investigated as a function of $\mathrm{pH}$ and contact time in a batch mode. It was found that, the maximum uptake of phenol take place at $\mathrm{pH}$ 4. The kinetic data were fitted well to the models of pseudo second order and Elovich, and followed closely the Elovich chemisorption model. While the Freundlich isotherm model fitted the experimental data much better than the Langmuir model.

\section{Acknowledgement}

The financial assistance from Universiti Teknologi PETRONAS (UTP) is gratefully acknowledged for enabling this research work to be undertaken.

\section{References}

[1] Jern, N.W., Industrial Wastewater Treatments, Imperial College Press, Covent Garden, London, pp. 12-14, 2006.

[2] Nayak, P.S. \& Singh, B. K., Removal of phenol from aqueous solutions by sorption on low cost clay, Desalination, 207, pp. 71-79, 2007.

[3] Busca, G., Berardinelli, S., Resini, C. \& Arrighib, L., Technologies for the removal of phenol from fluid streams: A short review of recent developments, Journal of Hazardous Materials, 160, pp. 265-288, 2008.

[4] Ahmaruzzaman, M. \& Sharma, D.K, Adsorption of phenols from wastewater Journal of Colloid Interface Science, 287, pp. 14-24, 2005.

[5] Aksu, X., Application of biosorption for the removal of organic pollutants: a review, Process Biochemistry. 40, 997-1026, 2005. 
[6] Jain, A.K. \& Suhas \& Bhatnagar, A., Methylphenols removal from water by low-cost adsorbents, Journal of Colloid Interface Science, 251, pp. 3945, 2002.

[7] Altenor, S., Carene, B., Emmanuel, E., Lambert, J., Ehrhardt, J-J. \& Gaspard, S., Adsorption studies of methylene blue and phenol onto vetiver roots activated carbon prepared by chemical activation, Journal of Hazardous Materials,165, pp. 1029-1039, 2009.

[8] Cherifi, H., Haninia, S. \& Bentahar, F., Adsorption of phenol from wastewater using vegetal cords as a new adsorbent, Desalination, 244, pp. 177-187, 2009.

[9] Kumar, U. \& Bandyopadhyay, M., Sorption of cadmium from aqueous solution using pretreated rice husk, Bioresource Technology, 97, pp. 104 109, 2006.

[10] Chuah, T.G., Jumasiah, A. , Azni, I. , Katayon, S. \& Thomas Choong, S.Y., Rice husk as a potentially low-cost biosorbent for heavy metal and dye removal: an overview, Desalination, 175, pp. 305-316, 2005.

[11] Ndazi, B.S., Karlsson, S., Tesha, J.V. \& Nyahumwa, C.W., Chemical and physical modifications of rice husks for use as composite panels, Composites: Part A: Applied science and manufacturing, 38, pp. 925-935, 2007.

[12] Asadi, F., Shariatmadari, H. \& Mirghaffari, N., Modification of rice hull and sawdust sorptive characteristics for remove of heavy metals from synthetic solutions and wastewater, Journal of Hazardous Materials, 154, pp. 451-458, 2008.

[13] El-Shafey, E.I. ., Sorption of Cd(II) and Se(IV) from aqueous solution using modified rice husk, Journal of Hazardous Materials, 147, pp. 546555, 2007.

[14] Hamdaoui, O. \& Naffrechoux, E., Modeling of adsorption isotherms of phenol and chlorophenols onto granular activated carbon. Part I. Twoparameter models and equations allowing determination of thermodynamic parameters, Journal of Hazardous Materials, 147, pp. 381-394, 2007.

[15] Ho, Y.S. \& Mckay, G., Comparative sorption kinetic studies of dye and aromatic compounds onto fly ash, Journal of Environmental. Science and Health, A34 (5), pp. 1179-1204, 1999.

[16] Aharoni, C. \& Tompkins, F. C., Kinetics of Adsorption and Desorption and Elovich Equation, Advances in Catalysis, 21, pp. 1-49, 1970.

[17] Lowell, S., Shields, J. E., Thomas, M. A. \& Thommes, M., Characterization of porous solids and powders: surface area, pore size and density, Netherlands: Springer, pp. 11-14, 2006.

[18] Srivastava, V. C., Mall, I.D. \& Mishra, I.M., Characterization of mesoporous rice husk ash (RHA) and adsorption kinetics of metal ions from aqueous solution onto RHA. Journal of Hazardous Materials, B134, pp. 257-267, 2006.

[19] Mahvi, A.H., Maleki, A. \& Eslami, A. , Potential of rice husk and rice husk ash for phenol removal in Aqueous System, American Journal of Applied Science, 1 (4), pp. 321-326, 2004. 